\title{
The Impact of Climate Change on the Value of Growing Maize as a Biofuel
}

\author{
Sally OLASOGBA, Les DUCKERS \\ Coventry University, UK
}

\begin{abstract}
:
Aim: According to COP23 Climate Change threatens the stability of the planet's ecosystems, with a tipping point believed to be at only $+2{ }^{\circ} \mathrm{C}$. With the burning of fossil fuels, held responsible for the release of much of the greenhouse gases, a sensible world- wide strategy is to replace fossil fuel energy sources with renewable ones. The renewable resources such as wind, hydro, geothermal, wave and tidal energies are found in particular geographical locations whereas almost every country is potentially able to exploit PV and biomass. This paper examines the role that changing climate could have on the growing and processing of biomass. The primary concern is that future climates could adversely affect the yield of crops, and hence the potential contribution of biomass to the strategy to combat climate change. Maize, a $\mathrm{C}_{4}$ crop, was selected for the study because it can be processed into biogas or other biofuels. Four different Nigerian agricultural zones (AEZ) growing maize were chosen for the study. Long-term weather data was available for the four sites and this permitted the modelling of future climates.
\end{abstract}

Design / Research methods: The results of this study come from modelling future climates and applying this to crop models. This unique work, which has integrated climate change and crop modelling to forecast yield and carbon emissions, reveals how maize responds to the predicted increased temperature, change in rainfall, and the variation in weather patterns. In order to fully assess a biomass crop, the full energy cycle and carbon emissions were estimated based on energy and materials inputs involved in farm management: fertilizer application, and tillage type. For maize to support the replacement strategy mentioned above it is essential that the ratio of energy output to energy input (the Net Energy, NE) exceeds 1, but of course it should be as large as possible.

Conclusions / findings: Results demonstrate that the influence of climate change is important and in many scenarios, acts to reduce yield, but that the negative effects can be partially mitigated by careful selection of farm management practices. Yield and carbon footprint are particularly sensitive to the application rate of fertilizer across all locations whilst climate change is the causal driver for the increase in net energy and carbon footprint at most locations. Nonetheless, in order to ensure a successful strategic move towards a low carbon future, and sustainable implementation of biofuel

Correspondence address: Sally Olasogba, Les Duckers, Coventry University, UK, E-mail: ab9358@coventry.ac.uk, olasogb2@uni.coventry.ac.uk (Sally Olasogba), L.Duckers@ coventry.ac.uk (Les Duckers).

Received: 27.06.2019, Revised: 13.12.2019, Accepted: 07.01.2020

doi: http://dx.doi.org/10.29015/cerem.838 
policies, this study provides valuable information for the Nigerian government and policy makers on potential AEZs to cultivate maize under climate change. Further research on the carbon footprint of alternative bioenergy feedstock to assess their environmental carbon footprint and net energy is strongly suggested.

Originality / value of the article: Unlike most studies, which focus only on farm energy use and historical climate change impact, this paper uses a fully integrated framework for the assessment of the impact of climate change on growing biofuels under various farm management practices. Thus it provides calculations of the net energy available from growing biofuel crops under future climates.

Keywords: Climate change, energy efficiency, life cycle analysis (LCA), climate models, Agricultural ecological zones (AEZs), carbon footprint $(C F)$.

JEL: Q4, Q13, Q54

\section{Introduction}

\subsection{The problem}

The concentration of greenhouse gasses in the upper atmosphere is currently over $410 \mathrm{ppm}$ (as equivalent in $\mathrm{CO}_{2}$ ): substantially above the pre-industrial level of $280 \mathrm{ppm}$, and rising to create global warming. A temperature increase of $2.0^{\circ} \mathrm{C}$ is predicted to take us through a tipping point, beyond which it may be impossible to stabilise the World's Climate. Replacing fossil fuels with renewable energy is an essential strategy to avoid reaching this tipping point and the renewable energy of concern in this paper is biofuel. Most countries can grow crops for energy.

Here we consider the question of the impact of the changing climate on the energy value of growing crops. A major question is whether future climates might reduce the crop yield, by how much, and if the crop represents a net positive contribution. For example, if the energy derived from a biofuel source is less than the energy used to plant, grow, harvest and process that biofuel then it should not be used in an energy strategy. We have taken maize in Nigeria as a sample crop, and assessed its response to climate change.

\subsection{The present situation}

Maize is a staple crop in Nigeria, used for food, and animal food, as a raw material for industrial products and biomass fuel (Olaniyan 2015). The world production of maize is dominated by the USA, which produces some $42 \%$, whilst Africa as a whole produces $6.5 \%$ and must import a quarter of its needs for food and 
commercial applications. Nigeria currently produces $8 \mathrm{Mt} / \mathrm{a}$ or about $1 \%$ of World production (Nwaogu et al. 2016).

Over the 12 months to July 2017 maize prices in Nigeria almost doubled from US\$ 274/t to US\$ 502/t (FoodBusinessAfrica 2017). The exchange rate in July 2017 was $£ 1=482$, US $\$=365 \AA$, making the maize crop worth about US $\$ 4$ b (USDA 2018). The Nigerian GDP was worth US\$405b in 2016 (World Bank 2016). Thus, the maize crop is extremely important to the Nigerian economy. The price rise is blamed, but without strong evidence, on various factors: A foreign exchange ban, effectively limiting maize imports to $0.2 \mathrm{Mt} / \mathrm{a}$ and causing commercial buyers to pay higher prices for a limited local supply, macro-economic uncertainties, spot buying at the farm gate by poultry farmers, insurgency in the north east of Nigeria, infestation of army worms. Growing maize as an energy crop, by producing ethanol, is thus in competition with growing it as a raw material, or as food. In terms of maize as a biofuel feedstock, ethanol, produced from maize has an energy content of 1.2 to 1.45 times the energy input (Liska et al. 2009). This is sufficient for it to be a valuable positive energy contributor, with low $\mathrm{CO}_{2}$ emissions.

\section{Modelling strategy}

\subsection{Modelling the likely impact of climate change on the yield of maize}

Future climates are dominated by the influence of the enhanced greenhouse effect, resulting from the increased $\mathrm{CO}_{2}$ concentration in the upper atmosphere, which traps long wavelength radiation, leading to temperature increase. The climate change, though, is not limited to a simple temperature increase, but to more chaotic weather: longer episodes of flood and drought, more storms and unsettled conditions. Sea level rise will compromise coastal regions. In terms of growing crops, we might anticipate that warmer conditions will aid crop yield, but in fact, higher temperatures can be counterproductive. Also crucial to successful crop growth is the availability of water and so episodic variations in rainfall could be a dominating damaging factor. 
In order to model the crop yield under future climates, four Nigerian sites representing different agro-geographical zones were selected (see Figure 1). Historical weather data was collected for all sites, and this was used to calibrate and validate a climate model. The climate model, which consists of an ensemble of 40 GCMs, was then programmed to predict future climates under two representative scenarios: RCP 6.0 and RCP 8.5 for 2020, 2050 and 2080 timelines.

\section{Figure 1. Solar insolation in Nigeria showing the location of the selected sites}

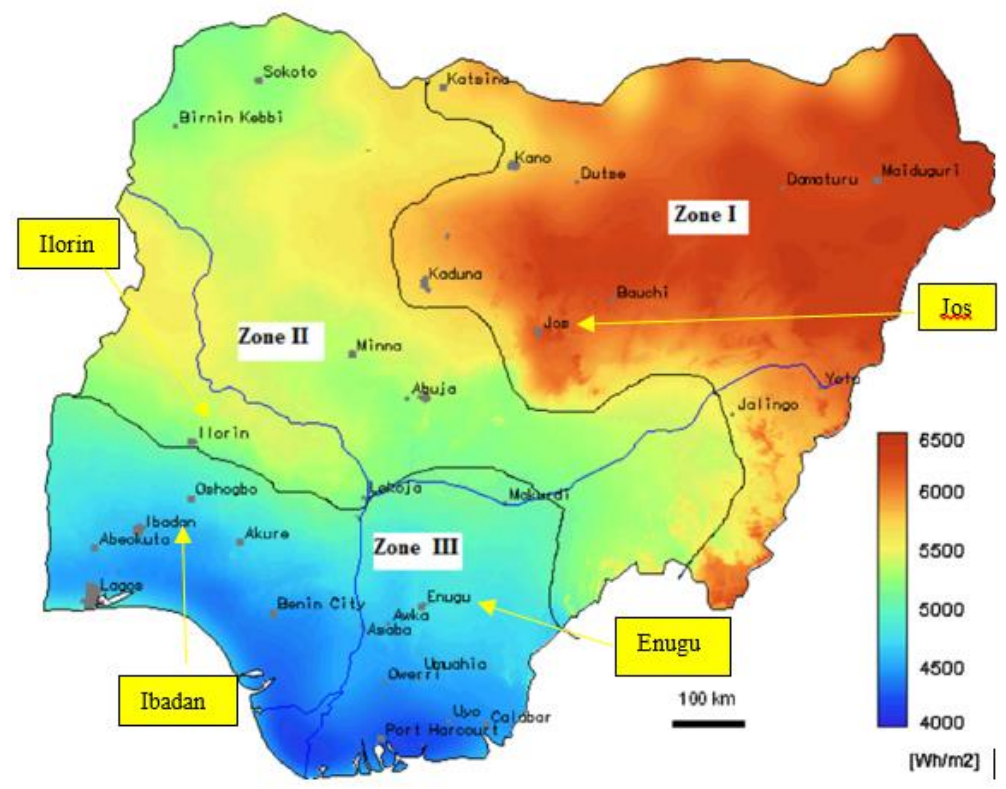

Source: Ohunakin et al. (2014).

Based on the projected GCM results, which are indicative of gradual sitespecific warming (see Figures 2 and 3), it is highly likely that climate change will have profound effect on maize crop productivity in the agro-ecological zones studied. Similar to Mereu et al. (2018), higher maize yield reduction in the Southern Guinea savannah of Nigeria (Ilorin) was due to a projected temperature increase of above $2^{\circ} \mathrm{C}$, projected under the RCP 8.5 emission scenario especially. 
Figure 2. Scatter plot used to visualise the spread of future changes in rainfall (\%) and mean temperature $\left({ }^{\circ} \mathrm{C}\right)$ with respect to baseline under RCP6.0 scenario. Each scenario year is colour coded (green - 2020; blue - 2050; red 2080)

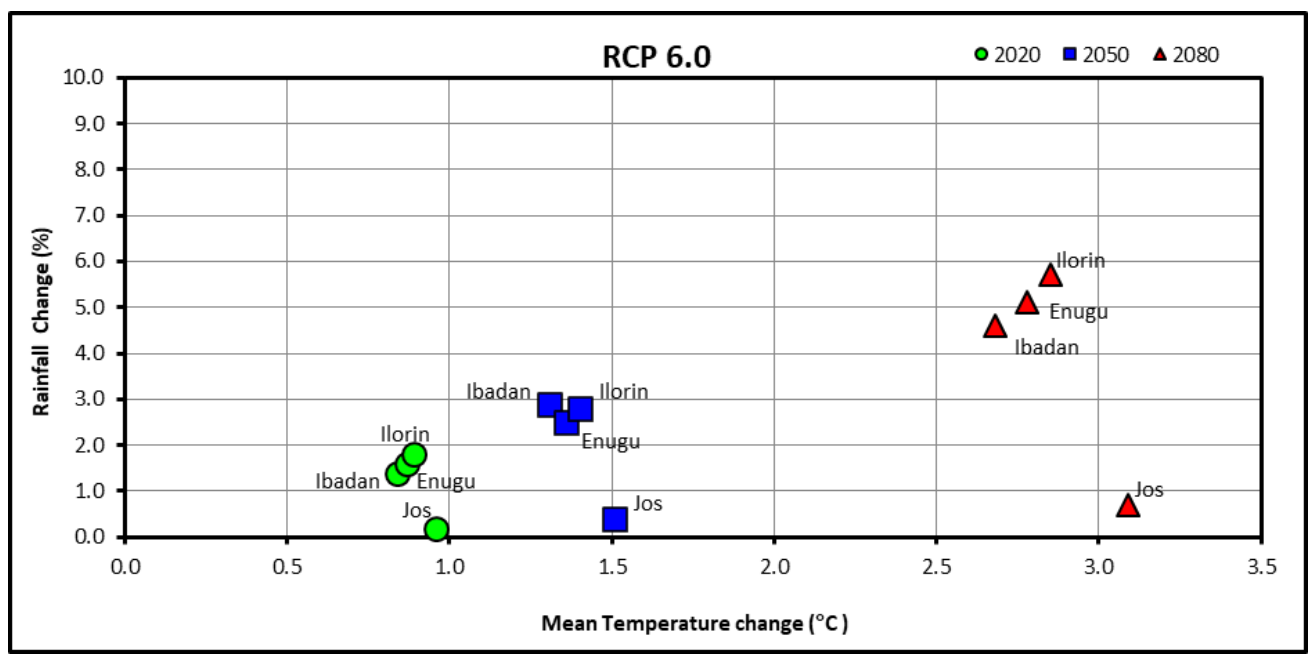

Source: Data processed by authors.

Figure 3. Scatter plot used to visualise the spread of future changes in rainfall (\%) and mean temperature $\left({ }^{\circ} \mathrm{C}\right)$ with respect to baseline under RCP 8.5 scenario. Each scenario year is colour coded (green - 2020; blue - 2050; red 2080)

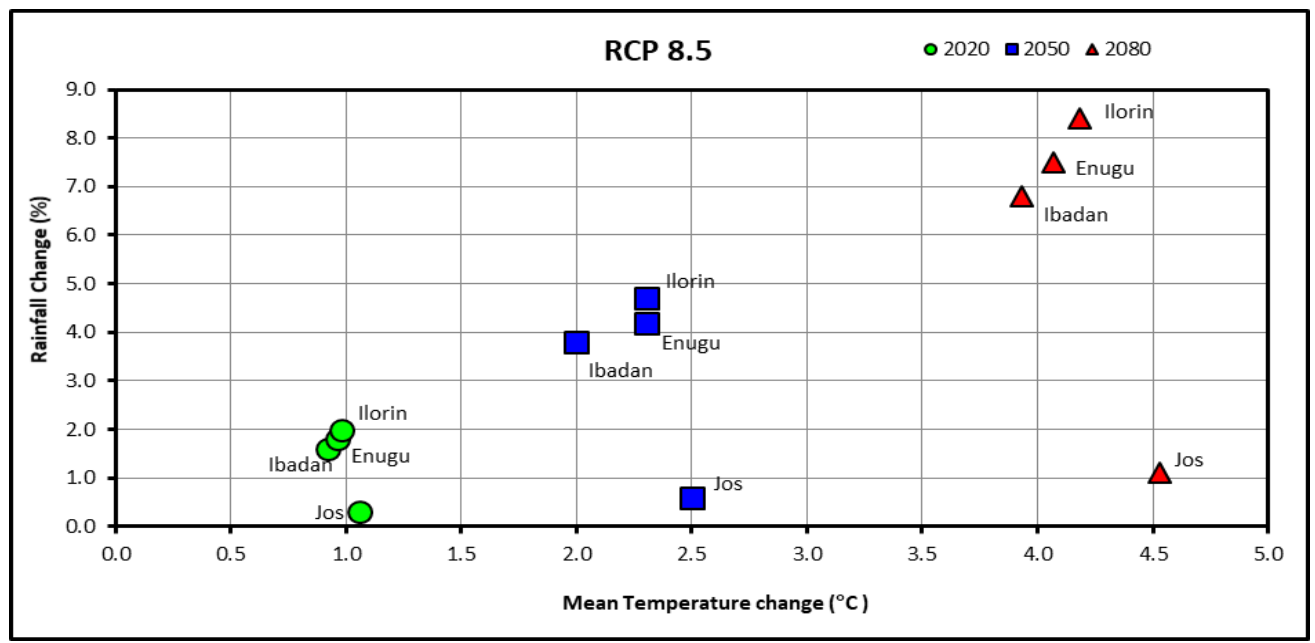

Source: Data processed by authors. 
Results show that average projected temperature will increase by $2.4{ }^{\circ} \mathrm{C}$ and 3.3 ${ }^{\circ} \mathrm{C}$ towards the year 2080 relative to a 2010 climate baseline. Likewise, rainfall will increase slightly ( \pm 0.3 to $\pm 8 \%$ ) across the locations studied: Ibadan, Jos, Enugu and Ilorin. Hence, adequate adaptation measures will be required to overcome the effects of these climatic changes on crop yield. Based on evidence from the latest IPCC AR5 report (2014), global warming in Africa is likely to become larger than global annual average warming (Niang et al. 2014; Hartley et al. 2015). The impact of climate change on yields of major cereal crops in sub-Saharan Africa will be negative overall, with strong regional variation in terms of the degree of reduction (Niang et al. 2014; Ezeaku et al. 2014; Parkes et al. 2018). Although different GCMs tend not to agree with predictions of the average amount of rainfall for the region, there is a consensus that the inter-annual variability of the amount of rainfall will increase (Traore 2014). According to Magugu (2016), local physiographic and atmospheric effects makes future rainfall projections less certain compared with temperature projections.

Climate change impact on maize yield varied across locations within the Derived savannah and Southern Guinea savannah AEZs. Maize yield increased in Jos, Enugu and Ilorin for both projected scenarios (RCP 6.0 and 8.5) and declined as the timeline shifted from 2020 to 2050, further declining below baseline levels by 2080. Climate change reduced yield under all scenarios in Ibadan compared to baseline yield (see Figures 4 and 5). The general decline in maize yield from year 2020 to 2080 suggests a greater negative influence due to warmer climate. This result is consistent with the projections of Corbeels et al. (2018) who found average maize yield would significantly decline in Southern Africa under the RCP 8.5 scenario. Increase in maize yield variability in response to climate change was positive for all location, which according to Parkes et al. (2018) represents a risk of crop failure and loss especially for northern and southern Nigeria. 
Figure 4. Chart of simulated maize yield output for baseline and RCP 6.0 scenarios for the period 2020-2080 at four study sites

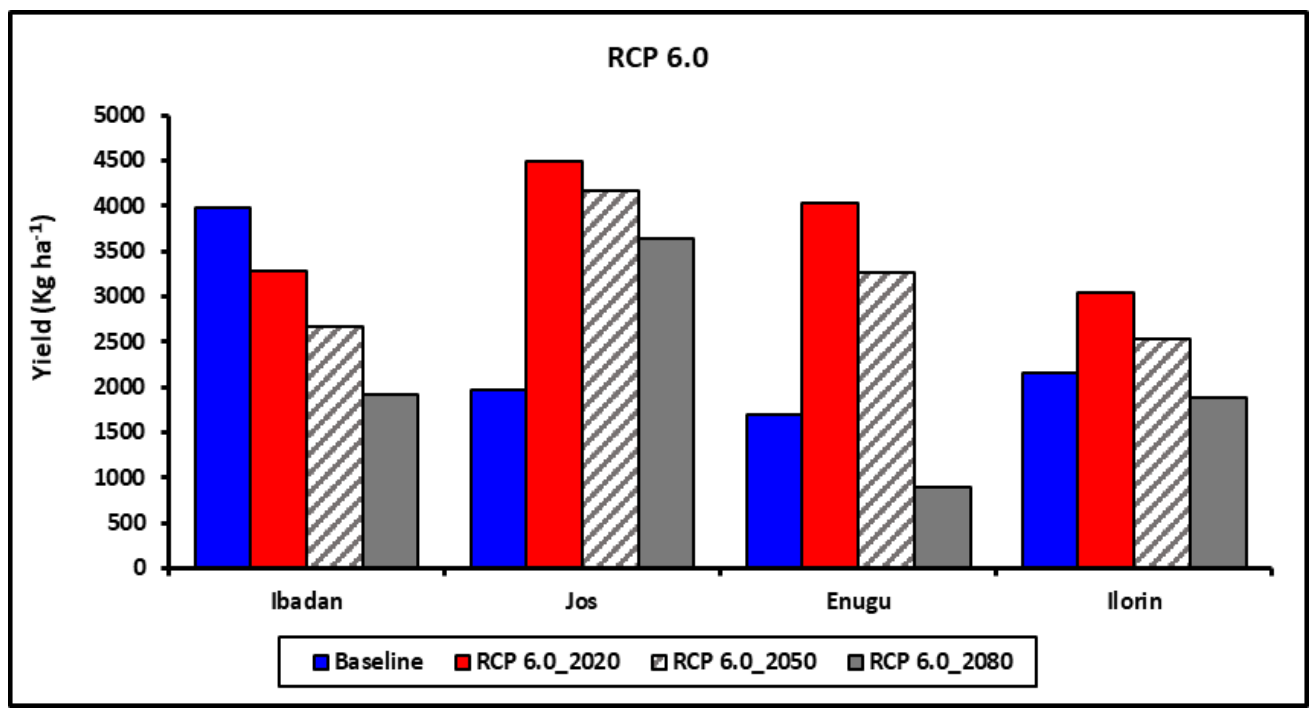

Source: Data processed by authors.

Figure 5. Chart of simulated maize yield output for baseline and RCP 8.5 scenarios for the period 2020-2080 at four study sites

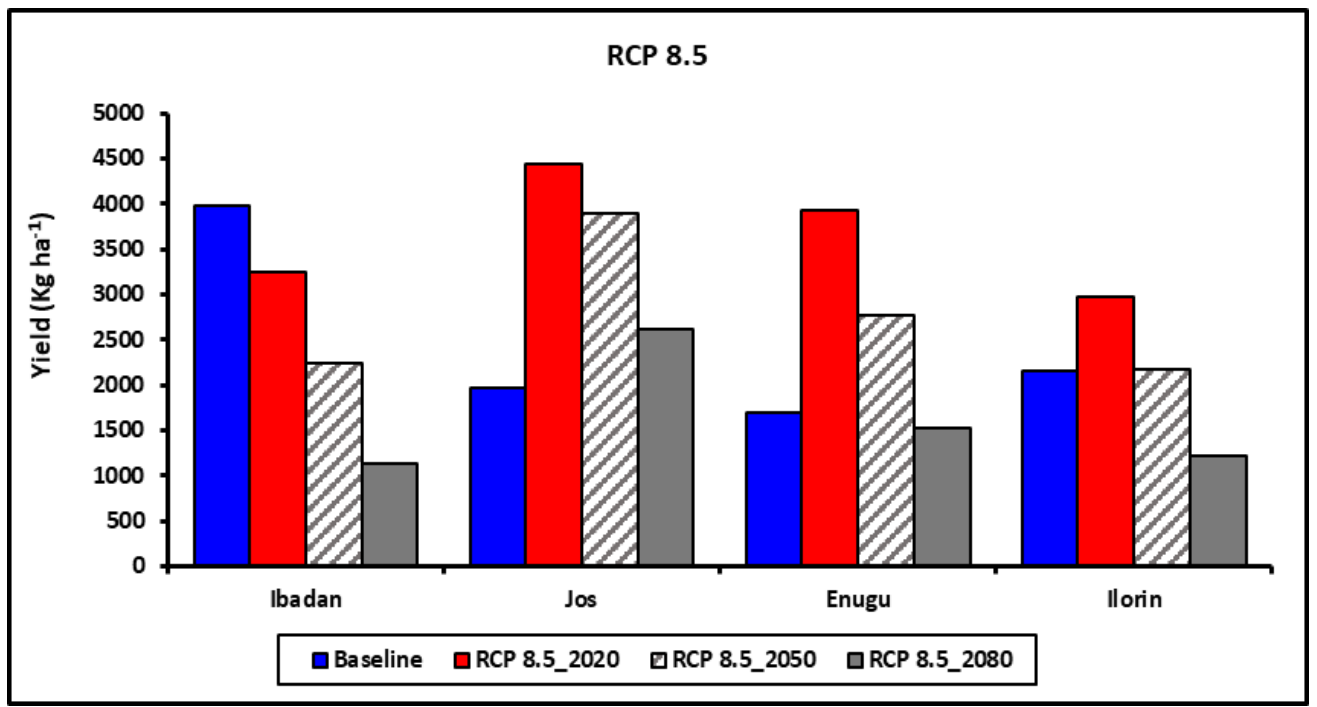

Source: Data processed by authors. 
Optimal fertiliser application is an adaptation strategy in the event of climate change impact on crop yield (Nasim et al. 2016; Mahama, Maharjan 2017). Maize yield response to varying nitrogen fertiliser rates (from $80 \mathrm{~kg} \mathrm{~N}^{-1}$ to $250 \mathrm{~kg} \mathrm{~N}^{-}$ ${ }^{1}$ ) was evaluated. The optimal application rate was $160 \mathrm{~kg} \mathrm{~N}^{-1}$ with the exception of one location (Jos) in the Southern Guinea savannah AEZ which required higher application rates (200 $\mathrm{kg} \mathrm{N} \mathrm{ha}^{-1}$ to $250 \mathrm{~kg} \mathrm{~N} \mathrm{ha}^{-1}$ ) to obtain maximum yield under both climate scenarios. Further evaluation of different maize genotypes is required to determine yield response to optimal fertiliser rates as suggested in this study under climate change.

\subsection{Evaluation of maize as a future biofuel feedstock}

The environmental impact assessment of a farming system using the LCA framework is very common. This is because its holistic approach makes it possible to identify hot spots for environmental pollution, but also to avoid pollution tradeoffs across the life-cycle stages (Bessou et al. 2013). This study applied a streamlined LCA method that focused specifically on a maize production system within the biofuel production network.

Energy use in maize production was estimated by varying both farm management practices and equipment energy input. Results show that climate change affected all energy indicators used to assess the efficiency of maize production but by varying degrees for each location studied, and dependent on the tillage method (CT, RT, NT) and fertiliser application rate $\left(80 \mathrm{~kg} \mathrm{~N} \mathrm{ha}^{-1}, 160 \mathrm{~kg} \mathrm{~N}\right.$ $\mathrm{ha}^{-1}, 200 \mathrm{~kg} \mathrm{~N} \mathrm{ha}^{-1}, 250 \mathrm{~kg} \mathrm{~N} \mathrm{ha}^{-1}$ ) adopted. Increasing fertiliser rates increased total energy input with a consequent reduction in energy use efficiency. The direct environmental effects as a result of the release of $\mathrm{CO}_{2}$ and other GHG emissions, as well as the excessive use of natural resources are global concerns that must be addressed through efficient use of material inputs. A higher proportion of input energy was attributed to nitrogen fertiliser and diesel fuel in all 12 management scenarios, with averages of $71 \%$ and $14 \%$ respectively. The NT tillage system and a low fertiliser input of $80 \mathrm{~kg} \mathrm{~N} \mathrm{ha}^{-1}$ (160 $\mathrm{kg} \mathrm{N} \mathrm{ha}^{-1}$ for maximum yield output) show a potential to reduce total energy input by a significant amount and could translate to 
reduced operational costs for farmers. These combinations should seriously be considered for future maize cultivation systems.

Energy output ( $\mathrm{MJ} \mathrm{ha}^{-1}$ ) was positive for all climate change scenarios, which represents energy gain for maize produced. However, when compared to the baseline, energy gained reduced as climate change progressed to the year 2080 across all four AEZs, despite the application of a higher amount $\left(250 \mathrm{~kg} \mathrm{~N} \mathrm{ha}^{-1}\right)$ of synthetic nitrogen fertiliser (see Figure 6). The effect of using different tillage practices under future climate scenarios did not improve the overall energy output. The lowest energy use efficiency was predicted for the year 2080 under RCP 8.5 scenario but the efficiency improved across all scenarios by reducing soil tillage practices (NT tillage system). The system net energy value (NE) was positive which represents energy gain for all sites but the values reduced under climate change scenarios. Higher NE gain was obtained by adopting the NT method at Jos, Ilorin and Enugu but the CT tillage system was more beneficial at Ibadan.

Figure 6. Energy output (MJ ha ${ }^{-1}$ ) deviations of RCP 6.0 and 8.5 scenarios from baseline at Ibadan, Jos, Ilorin and Enugu sites. Results are based on $250 \mathrm{~kg} \mathrm{~N}$ ha $^{-1}$ rate. CT- (Conventional tillage); RT - (Reduced tillage); NT - (No tillage)
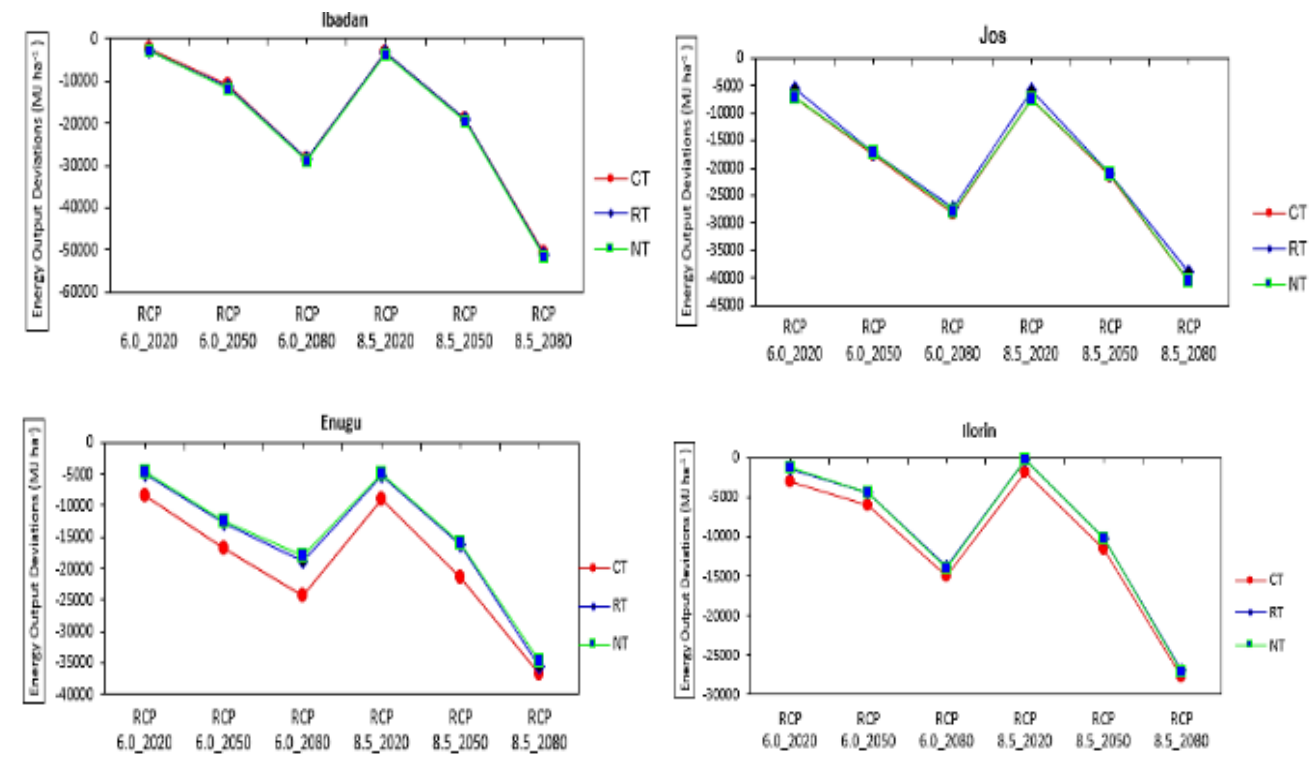

Source: Data processed by authors. 
The LCA result shows the estimated emissions from soil due to fertiliser application adversely influenced the total GHG emissions, and carbon footprint increased per $\mathrm{kg}$ of maize produced. On average, total GHG emissions under farm management scenarios (fertiliser rate $\mathrm{x}$ tillage methods) was $2,931.4 \mathrm{~kg} \mathrm{CO}_{2} \mathrm{eq} \mathrm{ha}^{-1}$. These findings align with those of Ma et al. (2012) who reported a similar GHG emission range from a maize farm experiment based on three rotation systems. Direct and indirect soil $\mathrm{N}_{2} \mathrm{O}$ emissions associated with the application of urea fertiliser were the main emitters (53.4\%) followed by GHG emissions from the production of farm input materials $(37.8 \%)$. Within this category, $\mathrm{CO}_{2}$ emissions from fertiliser production was the highest. $\mathrm{CO}_{2}$ emissions from field machinery operation and from urea application (emission due to soil hydrolysis) contributed small shares to the total GHG emission ( $4.4 \%$ and $4.3 \%$ ). The impact of $\mathrm{N}$ fertiliser is therefore significant and underlines the importance of efficient $\mathrm{N}$ management. Studies have suggested that in addition to the split fertiliser method adopted in the simulation of crop yield, the use of enhanced efficiency fertilisers (EEFs) should also be utilised to maximise $\mathrm{N}$-use efficiency and the reduction of $\mathrm{N}_{2} \mathrm{O}$ emissions (Uchida, Rein 2018; Chen et al. 2018).

The carbon footprint (CF) per kg of maize grain produced was estimated based on the total GHG emissions from input production, field operation, soil emission, and the localised climate change impact on yield under farm management scenarios (see Figure 7). CF increased between 2020 and 2080 under both RCP 6.0 and 8.5 climate scenarios. The highest $\mathrm{CF}$ was associated climatically with the highest temperature increase scenario (RCP 8.5) in 2080, irrespective of the fertiliser rate or tillage system. This reflects the impact of harsher climate change on crop productivity compared to baseline. It indicates that generally, as grain yield declines under climate change, CF per kg of maize grain increases as expected, although with some exceptions. As an example, when considering CF response to fertiliser rates, results show that irrespective of the climate scenario, $\mathrm{CF}$ as well as yield increased as the amount of fertiliser increased. This was due to the higher GHG emissions (soil emissions) from higher fertiliser rate. Therefore, it did not matter if yield increased at any location, essentially, higher fertiliser rates affected CF per $\mathrm{kg}$ of maize grain produced (Qi et al. 2018). 
Figure 7. Carbon footprint ( $\mathrm{kg} \mathrm{CO} \mathrm{CO}_{2} \mathrm{eq}^{-1}$ yield) of maize grain production under baseline and two RCP climate scenarios: Jos (a) RCP 6.0 and (b) RCP 8.5; Ibadan (c) RCP 6.0 and (d) RCP 8.5

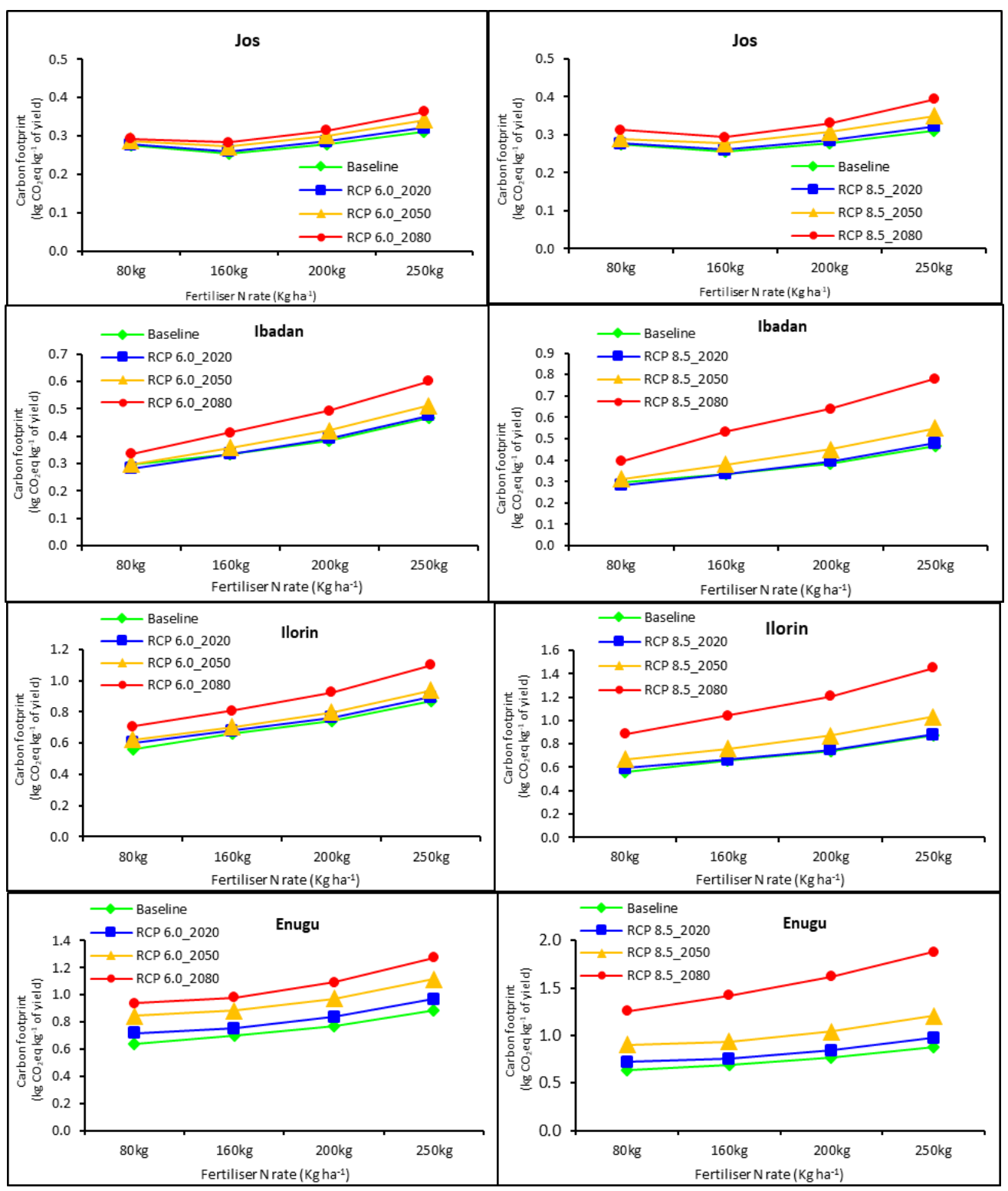

Source: Data processed by authors. 


\title{
3. Concluding remarks
}

Climate change will affect the yield of maize: but the impact may be positive in some locations and scenarios and negative in others. The variation in temperature, precipitation, and increasingly chaotic weather makes it difficult to predict the value of a particular crop. When the Net Energy approaches 1.0 the environmental cost of maize as a biofuel feedstock is just equal to the energy derived from it; meaning that when NE is less than 1.0 that maize becomes a negative energy source. Of course maize can also be used as a food, or commercial raw material, in which cases the energy balance is not necessarily applicable. Despite the huge potential for maize cultivation for biofuels, this may not be viable environmentally when climate change is factored in. Nonetheless, in order to ensure a successful strategic move towards a low carbon future, and sustainable implementation of biofuel policies, this study provides valuable information for the Nigerian government and policy makers on potential AEZs to cultivate maize under climate change. However, the approach used in this paper can be applied to all crops, for energy, food or raw material, and the technique used here will inform the policy on choice of crop type.

\author{
Abbreviations \\ GCM - Global Climate Model \\ RCP6.0 - Representative Concentration Pathway 6.0 \\ RCP8.5 - Representative Concentration Pathway 8.5 \\ CT - Conventional Tillage \\ RT - Reduced Tillage \\ NT - No Tillage \\ NE - Net Energy
}




\section{THE IMPACT OF CLIMATE CHANGE ON THE VALUE OF GROWING MAIZE ...}

\section{References}

Bessou C., Lehuger S., Gabrielle B., Mary B. (2013), Using a crop model to account for the effects of local factors on the LCA of sugar beet ethanol in Picardy Region, France, „The International Journal of Life Cycle Assessment”, vol. 18 no. 1, pp. 24-36, http://link.springer.com/10.1007/s11367-012-0457-0 [01.02.2017].

Corbeels M., Berre D., Rusinamhodzi L., Lopez-Ridaura S. (2018), Can we use crop modelling for identifying climate change adaptation options?, „Agricultural and Forest Meteorology”, no. 256-257 (March), pp. 46-52, https://doi.org/10.1016/j.agrformet.2018.02.026 [15.02.2020].

Ezeaku I.E., Okechukwu E.C., Aba C. (2014), Climate change effects on maize (zea mays) production in Nigeria and strategies for mitigation, „Asian Journal of Science and Technology”, vol. 5 no. 12, pp. 862-871.

FoodBusinessAfrica (2017), Soaring maize price in Nigeria defies two-year trend, https://www.foodbusinessafrica.com/2017/06/30/soaring-maize-price-in-nigeria-defies-two-year-trend/ [24.08.2018].

Hartley A., Jones R., Janes T. (2015), Projections of change in ecosystem services under climate change, http://www.unep-wcmc.org [26.12.2018].

Liska A.J., Yang H.S., Bremer V.R., Klopfenstein T.J., Walters D.T., Erickson G.E., Cassman K.G. (2009), Improvements in life cycle energy efficiency and greenhouse gas emissions of corn-ethanol, „Journal of Industrial Ecology”, vol. 13 no. 1, pp. 58-74, http://doi.wiley.com/10.1111/j.15309290.2008.00105.x [24.06.2019].

Ma B.L., Liang B.C., Biswas D.K., Morrison M.J., McLaughlin N.B. (2012), The carbon footprint of maize production as affected by nitrogen fertilizer and maize-legume rotations, „Nutrient Cycling in Agroecosystems", vol. 94 no. 1, pp. 15-31.

Magugu J.W. (2016), Agro-climatic change, crop production and mitigation strategies-case studies in Arkansas, USA and Kenya, PhD thesis, University of Arkansas, https://scholarworks.uark.edu/etd/1647 [13.08.2018].

Mereu V., Santini M., Cervigni R., Augeard B., Bosello F., Scoccimarro E., Spano D., Valentini R. (2018), Robust decision making for a climate- resilient development of the agricultural sector in Nigeria, in: Climate smart agriculture, Lipper L., McCarthy N., Zilberman D., Asfaw S., Branca G. (eds), Springer, Cham, pp. 277-306.

Niang I., Ruppel O.C., Abdrabo M.A., Essel A., Lennard C., Padgham J., Urquhart P. (2014), Africa, in: Climate change 2014. Impacts, adaptation, and vulnerability. Part B: Regional aspects. Contribution of Working Group II to the Fifth Assessment Report of the Intergovernmental Panel on Climate Change, Barros V.R., Field C.B., Dokken D.J., Mastrandrea M.D., Mach K.J., Bilir T.E., Chatterjee M., Ebi K.L., Estrada Y.O., Genova R.C., Girma B., Kissel E.S., Levy A.N., MacCracken S., Mastrandrea P.R., White L.L. (eds.), Cambridge University Press, Cambridge, pp. 1199-1265.

Nwaogu C., Olawoyin M.A., Kavianu V.A., Pavlů V. (2016), Soil dynamics, conservation and food supply in the Grassland Ecological Zone of Sub-Sahara Africa. The need for sustainable agroecosystem management for maize (zea mays), „Development, Environment and Foresight”, vol. 2 no. 2, pp. 6179, http://def-journal.eu/index.php/def/article/view/32 [21.06.2019]. 


\section{Sally OLASOGBA, Les DUCKERS}

Ohunakin O.S., Adaramola M.S., Oyewola O.M., Fagbenle R.O. (2014), Solar energy applications and development in Nigeria. Drivers and barriers, „Renewable and Sustainable Energy Reviews”, vol. 32, pp. 294-301.

Olaniyan A.B. (2015), Maize: panacea for hunger in Nigeria, „African Journal of Plant Science”, vol. 9 no. 3, pp. 155-174.

Parkes B., Defrance D., Sultan B., Ciais P., Wang X. (2018), Projected changes in crop yield mean and variability over West Africa in a world $1.5 \mathrm{~K}$ warmer than the pre-industrial era, „Earth System Dynamics", vol. 9 no. 1, pp. 119-134.

Traore B. (2014), Climate change, climate variability and adaptation options in smallholder cropping systems of the Sudano-Sahel Region in West Africa, PhD thesis, Wageningen University, https://agritrop.cirad.fr/575092/1/document_575092.pdf [15.02.2020].

USDA (2018), Nigeria. Grain and feed annual, https://gain.fas.usda.gov/Recent GAIN Publications/Grain and Feed Annual_Lagos_Nigeria_4-12-2018.pdf [25.01.2019].

World Bank (2016), Nigeria GDP Data, https://data.worldbank.org/indicator/NY.GDP.MKTP.CD?locations=NG [24.06.2018]. 